\title{
Outcomes of population based language promotion for slow to talk toddlers at ages 2 and 3 years: Let's Learn Language cluster randomised controlled trial
}

\author{
Melissa Wake professor and paediatrician ${ }^{1}$, Sherryn Tobin research officer ${ }^{1}$, Luigi Girolametto \\ professor of speech-language pathology ${ }^{2}$, Obioha C Ukoumunne statistician ${ }^{3}$, Lisa Gold health \\ economist ${ }^{4}$, Penny Levickis research assistant ${ }^{1}$, Jane Sheehan research assistant ${ }^{1}$, Sharon Goldfeld \\ paediatrician ${ }^{1}$, Sheena Reilly professor of speech pathology ${ }^{1}$
}

${ }^{1}$ Royal Children's Hospital, Murdoch Childrens Research Institute and University of Melbourne, Parkville, VIC 3052, Australia; ${ }^{2}$ Department of Speech-Language Pathology, University of Toronto, Toronto, ON, Canada, M5G 1V7; ${ }^{3}$ PenCLAHRC, Peninsula College of Medicine and Dentistry, University of Exeter, Exeter, UK; ${ }^{4}$ Deakin Health Economics, Deakin University, Burwood, VIC 3125, Australia

\begin{abstract}
Objective To determine the benefits of a low intensity parent-toddler language promotion programme delivered to toddlers identified as slow to talk on screening in universal services.

Design Cluster randomised trial nested in a population based survey. Setting Three local government areas in Melbourne, Australia.

Participants Parents attending 12 month well child checks over a six month period completed a baseline questionnaire. At 18 months, children at or below the 20th centile on an expressive vocabulary checklist entered the trial.

Intervention Maternal and child health centres (clusters) were randomly allocated to intervention (modified "You Make the Difference" programme over six weekly sessions) or control ("usual care") arms.

Main outcome measures The primary outcome was expressive language (Preschool Language Scale-4) at 2 and 3 years; secondary outcomes were receptive language at 2 and 3 years, vocabulary checklist raw score at 2 and 3 years, Expressive Vocabulary Test at 3 years, and Child Behavior Checklist/1.5-5 raw score at 2 and 3 years.

Results 1217 parents completed the baseline survey; 1138 (93.5\%) completed the 18 month checklist, when 301 (26.4\%) children had vocabulary scores at or below the 20th centile and were randomised (158 intervention, 143 control). 115 (73\%) intervention parents attended at least one session (mean 4.5 sessions), and most reported high satisfaction with the programme. Interim outcomes at age 2 years were similar in the two groups. Similarly, at age 3 years, adjusted mean differences (intervention-control) were -2.4 (95\% confidence interval -6.2 to $1.4 ; P=0.21)$ for expressive language; $-0.3(-4.2$ to $3.7 ; P=0.90)$ for receptive language; $4.1(-2.3$ to $10.6 ; P=0.21)$ for vocabulary checklist; -0.5 (-4.4 to $3.4 ; \mathrm{P}=0.80$ ) for Expressive Vocabulary Test;
\end{abstract}

-0.1 ( -1.6 to $1.4 ; \mathrm{P}=0.86)$ for externalising behaviour problems; and $-0.1(-1.3$ to $1.2 ; P=0.92)$ for internalising behaviour problems.

Conclusion This community based programme targeting slow to talk toddlers was feasible and acceptable, but little evidence was found that it improved language or behaviour either immediately or at age 3 years. Trial registration Current Controlled Trials ISRCTN20953675.

\section{Introduction}

Approximately 5-8\% of preschool children have a delay in their language development that persists throughout the school years and into adulthood. ${ }^{1-5}$ Persistent language delay is associated with poorer school and academic performance, more limited employment opportunities, and difficulties with social interactions and relationships. ${ }^{2}$ Higher rates of behavioural problems may compound poorer educational, social, and employment outcomes. ${ }^{24} 6$

One important risk factor for early language delay is a restricted size of expressive vocabulary at 18-24 months of age, ${ }^{7}$ typically assessed using standardised parental report instruments that are inexpensive and reliable and predict later language outcomes. ${ }^{7-10}$ Theoretical views of language acquisition consider that development of vocabulary provides a foundation for future grammatical development. ${ }^{11}$ Delays in expressive vocabulary, in the absence of neurological, sensory, or cognitive deficits, affect approximately $15-20 \%$ of 2 year olds. ${ }^{12}{ }^{13}$ Untreated delays in toddlers have persistence rates of $40-60 \%,{ }^{5}$ and limited evidence suggests that earlier detection may lead to more timely access to speech and language services and fewer children needing specialised interventions at school age. ${ }^{14} 15$

Early preventive interventions have the potential to allay parental concerns, improve children's language outcomes, and 
subsequently expedite entry into more intensive services for those most in need. A relatively low cost option is to teach parents to optimise their responsive behaviours (for example, responding to the child's focus of interest) and provide rich language input (for example, expanding the child's attempts to talk). ${ }^{16-18}$ Parent based programmes have been reported to improve the short term language outcomes of children at risk and to reduce delays in expressive vocabulary development. ${ }^{16-19}$ A recent meta-analysis of intervention trials showed much larger effect sizes for younger children with language delay (aged approximately 2 years) than for older children. ${ }^{20}$ Language intervention may also improve behaviour and socialisation. ${ }^{17}{ }^{21}$

In 2006 the US Preventive Services Task Force released its systematic review of evidence for screening for speech and language delay in preschool children. ${ }^{5}$ It called for larger studies ( $>50$ in each arm), longer term follow-up (at least 12 months), studies in children aged under 2 years, and consideration of "the balance of benefits and harms of using brief, formal screening instruments . . . for . . . language delay in the primary care setting." The trial reported here was planned to consider each of these factors and, specifically, an evidence gap for population based selective prevention. Selective prevention involves offering a low intensity intervention to a relatively large minority of the population with an identified strong risk factor, rather than to the smaller group that might meet diagnostic criteria if detailed assessment were available.

We report the outcomes in 2 year olds and 3 year olds of a parent based language promotion programme in Melbourne, Australia, that targets 18 month old toddlers at risk of language delay by virtue of the absence or near absence of spoken words. We chose this entry point because we wanted to offer a true selective prevention (rather than early treatment) intervention; our universal services have very high capture rates at this age; parents are typically very concerned about absence of language at 18 months and so would be very motivated to participate; the programme would not be stigmatising, because of its overtly preventive nature and the fact that $20 \%$ of all children would be involved; and, if the programme was rolled out in Australia, the upcoming 2 year old well child visit (the last until age 3.5 years) could act as a funnel into more detailed assessment and individual referral for those who did not seem to benefit from the preventive programme.

The Hanen Centre developed the preventive programme "You Make the Difference", a parent-toddler language promotion programme. ${ }^{22}$ It has been previously pilot tested with parents of at risk toddlers, ${ }^{23}{ }^{24}$ showing a high degree of parental satisfaction with the programme's format, content, and outcomes. We aimed to determine whether translating the programme to a low intensity population based screening approach delivered to all toddlers with slow early development of expressive vocabulary would improve children's language development outcomes at 2 and 3 years (the primary outcome) and reduce behavioural problems (particularly externalising ones).

\section{Methods \\ Study design}

This cluster randomised trial was nested within a population survey in three of the 31 local government areas comprising greater Melbourne (population 3592591 in 2006), Australia. The three areas comprise a diverse population including areas of lower (Frankston), middle (Banyule), and upper (Kingston) socioeconomic status as measured by the Australian census derived Socio-Economic Indexes For Areas (SEIFA) Index of
Disadvantage. ${ }^{25}$ The survey and trial were informed by a pilot randomised trial (ISRCTN45091963). ${ }^{24}$

\section{Participants}

All newborn infants in Melbourne are allocated to a local maternal and child health nurse who provides developmental care to age 5 years. Nurses pre-identified all infants born in May-October 2006 (Banyule, Kingston) or June-December 2006 (Frankston) and, at their 12 month visit (or by mail if they did not attend), ascertained interest in the trial. Children were excluded if they had already been referred for cognitive delay, major medical conditions, or suspected autism spectrum disorder or if parents had insufficient English to complete the questionnaires (written at a year 6 level of English) or participate in the programme. The research team then contacted interested families and mailed baseline questionnaires and written informed consent forms. Parents consented simultaneously to the baseline survey and entry into the trial if subsequently eligible, enabling us to determine the true uptake of the intervention.

At 18 months, the research team mailed recruited parents the screening expressive vocabulary and behaviour checklists. We determined eligibility for the trial by a score at or below the 20th centile on the expressive vocabulary checklist, based on population norms. ${ }^{26}$

\section{Randomisation and blinding}

Once recruitment was complete, we stratified maternal and child health centres (clusters) by local government area and randomly allocated them to intervention or "usual care"" (control) arms by using block randomisation with fixed block sizes of two after rank ordering the centres by the number of eligible children. A statistician not involved in enrolment computer generated the concealed allocation sequence, and the researchers who did outcome assessments were blinded to group allocation. Participants could not be blinded to group membership.

\section{Intervention}

The programme was a modified version of "You Make the Difference" 22 that was shortened from nine to six weekly sessions and supported by resources (guidebook, videotapes) for parents and training workshops for programme leaders. It promoted child centred, interaction promoting, and language modelling responsive interaction strategies; the intervention, its supporting theory, and its implementation are detailed in our report of the Let's Learn Language pilot study. ${ }^{24}$ Figure 1 summarises the content of the sessions. Over six weeks, weekly two hour sessions were held in the morning at a local community centre with child care available. In total, 20 programmes were offered; each included three to eight children and was led by one of three interventionists (one with a speech pathology background and two with psychology backgrounds) who had attended a three day Hanen training programme followed by specific training in the modified version.

The format is described in detail elsewhere. ${ }^{22}$ In brief, parents attended the first 1.5 hours while children were supervised in an adjacent room. In each session, the group leader started by reviewing the previous week's home practice and showing video clips of parent-child interactions to highlight previously learnt strategies; this was followed by a participative lecture. In the last 30 minutes, each parent and child pair was videotaped practising the new strategies with coaching as needed, from which a short positive clip was drawn for the group to view the following week to reinforce specific strategies. 


\section{Baseline measures}

At age 12 months (May-December 2007), parents reported demographic data and completed the Communication and Symbolic Behavior Scales Developmental Profile: Infant-Toddler Checklist (CSBS DP). ${ }^{27}$ At 18 months, parents completed the 100 word Sure Start expressive vocabulary screening measure, ${ }^{26}$ adapted from the MacArthur-Bates Communicative Development Inventory: UK Short Form, ${ }^{11}$ and further adapted by substituting two words for the Australian setting (cream cracker to cracker; settee/sofa to settee/sofa/couch). Our inclusion criterion cut-off point of the 20th centile corresponds to no or very limited spoken words. Parents also completed the Child Behavior Checklist (CBCL/1.5-5), ${ }^{28}$ a 99 item parent reported scale that generates scores for internalising and externalising behaviour problem subscales.

\section{Outcome measures}

At around age 2 years (12-14 weeks after the programme, May 2008 to February 2009), parents again completed the 100 word Sure Start measure and the Child Behavior Checklist. Trained research assistants visited the home to administer the Preschool Language Scale (PLS-4), ${ }^{29}$ a widely used measure that yields norm referenced scores for auditory comprehension (receptive communication) and expressive communication (our primary outcome). At age 3 years (May 2009 to March 2010), parents completed the MacArthur-Bates Communicative Development Inventory III (MCDI-III) and Child Behavior Checklist, and research assistants again visited the home to administer the Preschool Language Scale and the Expressive Vocabulary Test. These are both standardised to a normative mean of 100 (SD $15)$.

\section{Process measures}

Group leaders recorded parents' attendance. Parents in intervention clusters completed a short feedback questionnaire immediately after the final session, covering usefulness of the programme's format (sharing with other parents, practising strategies with the child, watching video clips, receiving feedback) and perception of changes in parent-child communication using a four point Likert-type scale. We dichotomised the scales into "high" and "low" values.

\section{Sample size}

We needed 100 participants and 20 maternal and child health centre clusters (five participants per cluster) in each arm to detect a mean difference of 0.6 standard deviations in expressive language with $90 \%$ power at the $5 \%$ level of significance, allowing for the clustered design and up to $20 \%$ attrition. This effect size was conservatively based on Law's 2004 systematic review of the efficacy of treatment for children with developmental language delay, ${ }^{20}$ in which the three included studies of parent delivered interventions yielded a pooled effect size of 0.83 ( $95 \%$ confidence interval -0.96 to 2.63 ) on preschool children's expressive syntax scores. The intra-cluster correlation coefficient estimate of 0.04 was based on the upper bound of the $95 \%$ confidence interval for the intra-cluster correlation coefficient at the level of the maternal and child health nurse for expressive vocabulary in the Early Language in Victoria Study. ${ }^{12}{ }^{30} \mathrm{We}$ calculated the number of participants needed in each cluster on the basis of the availability of 40 study clusters. ${ }^{31}$ We aimed to recruit around 1000 babies at 12 months, assuming that $20 \%$ would be eligible for the trial at 18 months.

\section{Statistical analysis}

Using the intention to treat principle, we compared mean outcome scores between the trial arms by using random effects linear regression models with maximum likelihood estimation to allow for cluster effects. ${ }^{32}$ Unadjusted analyses were followed by analyses adjusted for sex, exact age at outcome assessment, local government area, three indicators of socioeconomic status (parent's education level, household income, Socio-Economic Indexes For Areas (SEIFA) disadvantage score of the participant's home address), the 12 month Communication and Symbolic Behavior Scales Developmental Profile score, and the screening vocabulary score at 18 months. We also adjusted analyses of the behaviour outcomes for the corresponding 18 month score. Finally, we did 12 retrospective tests of interaction to explore whether any indication of differential effect of the intervention on any of the three main outcomes (expressive, receptive, and vocabulary scores) existed at each of the two time points ( 2 and 3 years of age) between the categories of 18 month vocabulary status ( $\leq 10$ th centile $v>10$ th centile) at 18 months and mother's education level (did not complete school $v$ school completion or higher).

\section{Results}

Figure 2 summarises the flow of participants through the trial. Of the 1414 eligible and contactable children referred to the language survey, 1217 (86.1\%) were recruited; of these, 1138 (93.5\%) completed the 18 month vocabulary screen, of whom $301(26.4 \%)$ entered the trial (158 intervention, 143 control) on the basis of their screening score. In the intervention arm, 115 (73\%) parents attended at least one session (mean 4.5 (SD 1.6, range 1-6) sessions), and 90 (57\%) parents attended four or more sessions. On average, children with lower baseline vocabulary attended more sessions $(\mathrm{P}=0.03)$; mean baseline vocabulary scores at 18 months were 6.0 (SD 2.9) for those who attended no sessions, 5.5 (2.6) for those who attended one to three sessions, and 4.6 (2.9) for those who attended four to six sessions.

Retention was high in both arms: $94 \%(148 / 158)$ for the intervention arm and 96\% (137/143) for the control arm at 2 years and $89 \%$ for both the intervention arm (140/158) and the control arm (127/143) at 3 years. The assessments for 2 year olds took place at a median of 14 (interquartile range 13-16) weeks after the programme. Table 1 shows that no marked differences existed in baseline characteristics between the trial arms and that their follow-up took place at similar ages.

\section{Language, vocabulary, and behaviour outcomes}

Table 2 shows the unadjusted and adjusted comparisons between the intervention and control arms at ages 2 and 3 years. We found little evidence of a difference between the two arms, which had similar means for all outcomes.

\section{Parents' evaluations of programme format and outcomes}

Table 3 shows that between 71 and 88 (76-89\%) of the parents rated each aspect of the programme's instructional format positively. In addition, of the 100 parents asked to give feedback, 86 thought that the programme had led to positive changes in how they communicated with their children, 72 reported positive changes in their children's communication, and 62 reported changes in their children's behaviour. Finally, 47 (76\% of 62) 
parents who had other children reported benefits in how they communicated with them.

\section{Missing data}

Some participants had data missing for outcomes, confounders, or both, so that the reported analyses did not include all participants. Analyses of 20 imputed complete datasets, generated by using multivariate normal imputation, ${ }^{33}$ provided results that indicated essentially the same conclusions as the complete case analyses reported here.

\section{Retrospective interaction analyses}

We found some evidence at the $5 \%$ level of effect modification for three of the 12 tests for interaction, pertaining to receptive language scores only. The intervention seemed to be relatively less effective in children with 18 month vocabulary scores at or below the 10th centile (at 2 and 3 years, $P=0.004$ for both) and in children whose parent did not complete school (at 3 years only, $\mathrm{P}=0.04)$.

\section{Discussion}

This six week, parent based programme was rated very positively by parents and was not harmful. However, we found little evidence that it improved vocabulary, language, or behavioural outcomes when delivered as a preventive programme to toddlers identified by population based screening as being at risk of language delay by virtue of having few or no spoken words at 18 months. The programme would be costly to provide at a population level, as it would involve around a quarter of the population of toddlers each year. It would also be unnecessary because, although these slow to talk toddlers had low mean language scores at age 2 , by 3 years they had achieved mean expressive, receptive, and vocabulary scores very similar to population norms.

\section{Strengths and limitations of study}

Strengths of the study include a high population reach and uptake in communities across the demographic spectrum, careful pilot testing of the programme's protocol to ensure acceptability and feasibility, random allocation to groups, excellent uptake and retention, blinding of outcome assessment, and large sample size (a weakness in the literature for trials of childhood language $\left.{ }^{34}\right)$. Language outcomes were directly assessed with standardised measures, supplemented by parents' evaluations and measures of children's behaviour to investigate the programme's broader effect.

Several limitations must also be considered. Firstly, although the introduction outlines our good reasons for getting children to enter the trial at 18 months, this may simply be too young; too many children go on to spontaneously develop normal language (that is, the specificity is low). This is supported by the near normal mean language scores (table 2) achieved by age 3 years but was far from evident in the literature when we planned the trial. Perhaps prevention should be earlier and universal, with intervention offered only once language delay is definitely present - that is, only to older children. More recent reports indicate that later screening at 2.5 years may yield higher specificity and that interventions targeting 2-3 year old children identified as late talkers can be effective. ${ }^{16} 172135$ Either way, our findings have implications for policies on whether and when countries screen for language delay, a subject for which stronger evidence is sorely needed. ${ }^{5}$
Secondly, little is known about the selection of risk factors for language delay. We chose parents' report of development of expressive vocabulary, on the basis of the best evidence available. ${ }^{79} 10$ The vocabulary checklist accurately detects toddlers with no or small spoken vocabularies and has been the entry criterion for other trials in this age group,${ }^{16}$ although its long term predictive validity has been both criticised and defended. ${ }^{96}{ }^{37}$ Perhaps 18 months is not too young but, rather, we should have targeted other aspects such as receptive language. However, at age 2, our sample's mean receptive language score of around 90 was very similar to their low mean expressive language score, with rapid gains in both receptive and expressive scores towards the population mean of 100 by age 3 years. Furthermore, as receptive language is by definition less "overt" than spoken language, screening may also be more challenging.

Thirdly, the tests of interaction were not specified in advance, and we had no hypothesis as to what the nature of the interaction might be (which subgroups were most likely to respond differentially to the intervention). As the overall estimated comparison between the trial arms did not indicate an effect, the interaction findings, if true, would suggest benefit for receptive language to one subgroup but harm for the other, which has no strong basis. We take the view that these interaction results are most likely due to chance.

Finally, the intervention may have been insufficiently intensive in uptake, number of sessions received, or dose of intervention per session. ${ }^{38}$ Although we consider the uptake to be high for a population programme based on screening, only $57 \%$ of intervention families participated in at least four of the six weekly sessions; however, retrospective analyses indicate that those most in need (with lower vocabulary scores) were more likely to attend the programme. Even for parents who attended, six weeks may have provided insufficient exposure to consolidate the responsive interaction strategies. Longer interventions over 10-12 weeks have yielded positive outcomes with similar parent based interventions for more highly selected at risk and late talking children ${ }^{16-18}$; in contrast, low intensity may have explained the limited efficacy in Glogowska's randomised trial of community based speech and language therapy in older preschool children presenting clinically (whose language did not normalise over the follow-up period). ${ }^{39}$ However, the normal mean language and vocabulary scores achieved by both intervention and control children by age 3 years suggest that natural resolution, rather than our intervention's intensity being too low, explains the null findings.

\section{Conclusions and policy implications}

Studies with both positive and null findings need to be considered in making informed decisions about the effectiveness of prevention strategies, ${ }^{404}$ particularly given the public pressure to respond earlier to a range of language concerns in young children. We caution against assuming that good interventions will remain effective when translated to the population level. This study shows the wisdom of doing rigorous trials to avert the considerable waste of governments' and families' resources that may otherwise occur.

Interventions of greater intensity, delivered at a different age, or both may yet prove helpful, although we recognise that this may put them out of the reach of implementation in the population. Alternatively, efforts may need to focus on improving both the sensitivity and specificity of measures to target interventions better to the young children most at risk of lasting language problems. ${ }^{5}$ Given the societal cost of these 
problems, pursuing research into effective prevention and intervention for all these children is essential.

We thank the participating maternal and child health nurses and families, the members of the project's advisory group for their interest and support throughout, and all the research assistants who delivered the programme and did the follow-up assessments.

Contributors: As the chief investigators, MW, LGirolametto, OU, LGold, $\mathrm{SG}$, and SR were all closely involved with the trial. MW was the lead chief investigator, obtained the funding, and led the writing of the manuscript. LGirolametto and SR provided expertise on speech pathology. ST was the project manager, and PL and JS were senior research assistants. OU did the statistical analyses, and LGold did the economic analyses. All the authors read, edited, and contributed to the manuscript. MW is the guarantor.

Funding: The trial was funded by the Australian National Health and Medical Research Council (NHMRC) strategic award 384491. The following authors were supported by the NHMRC during the trial: MW (population health career development grant 546405); LGold (population health capacity building grant 425855), SG and OU (population health capacity building grant 436914), and SR (practitioner research fellowship 491210). Murdoch Childrens Research Institute's research is supported by the Victorian government's Operational Infrastructure Support Program. The researchers were independent of the funders.

Competing interests: All authors have completed the Unified Competing Interest form at www.icmje.org/coi_disclosure.pdf (available on request from the corresponding author) and declare: that MW, ST, LGirolametto, OU, LGold, PL, JS, SG, and SR have support from the NHMRC for the submitted work; the authors have no relationships with any companies that might have an interest in the submitted work in the previous three years; and the authors have no non-financial interests that may be relevant to the submitted work.

Ethical approval: The project was approved by the Royal Children's Hospital Ethics in Human Research Committee (EHRC 26028). All participating parents gave written informed consent.

Data sharing: No additional data available.

1 Tomblin JB, Records NL, Buckwalter P, Zhang X, Smith E, O'Brien M. Prevalence of specific language impairment in kindergarten children. $J$ Speech Lang Hear Res 1997;40:1245-60.

2 Tomblin JB, Zhang X, Buckwalter P, Catts $\mathrm{H}$. The association of reading disability, behavioral disorders, and language impairment among second-grade children. $J$ Child Psychol Psychiatry 2000;41:473-82.

3 Clegg J, Hollis C, Mawhood L, Rutter M. Developmental language disorders-a follow-up in later adult life: cognitive, language and psychosocial outcomes. $J$ Child Psychol Psychiatry 2005;46:128-49.

4 Beitchman J, Johnson C, Young A, Atkinson L, Escobar M, Wilson B, et al. Transitions to adulthood: developmental pathways from preschool to young adult linguistic, academic, and psychosocial outcomes. National Health Research and Development Program, 1999.

5 Nelson HD, Nygren P, Walker M, Panoscha R. Screening for speech and language delay in preschool children: systematic evidence review for the US Preventive Services Task Force. Pediatrics 2006;117:298-319.

6 Caulfield MB, Fischel JE, DeBaryshe BD, Whitehurst GJ. Behavioral correlates of developmental expressive language disorder. J Abnorm Child Psychol 1989;17:187-201.

7 Rescorla L. Age 17 language and reading outcomes in late-talking toddlers: support for a dimensional perspective on language delay. $J$ Speech Lang Hear Res 2009;52:16-30. Fenson L, Pethick S, Renada C, Cox J. Short-form versions of the MacArthur Communicative Development Inventories. Appl Psycholinguist 2000;21:95-116.

9 Feldman H, Dale PS, Campbell T, Colburn D, Kurs-Lasky M, Rockette H, et al. Concurrent and predictive validity of parent reports of child language at ages 2 and 3 years. Child Dev 2005;76:856-68.

10 Dale PS, Price T, Bishop D, Plomin R. Outcomes of early language delay: I. Predicting persistent and transient language difficulties at 3 and 4 years. $J$ Speech Lang Hear Res 2003:46:544.
11 Dale PS, Dionne G, Eley TC, Plomin R. Lexical and grammatical development: a behavioural genetic perspective. J Child Lang 2000;27:619-42.

12 Reilly S, Wake M, Bavin EL, Prior M, Williams J, Bretherton L, et al. Predicting language at 2 years of age: a prospective community study. Pediatrics 2007;120:1441-9.

13 Desmarais C, Sylvestre A, Meyer F, Bairati I, Rouleau N. Systematic review of the literature on characteristics of late-talking toddlers. Int J Lang Commun Disord 2007;1:30.

14 Van Agt $\mathrm{H}$, van der Stege $\mathrm{H}$, de Ridder-Sluiter $\mathrm{H}$, Verhoeven L, de Koning $\mathrm{H}$. A cluster-randomized trial of screening for language delay in toddlers: effects on school performance and language development at age 8. Pediatrics 2007;120:1317-25.

15 De Koning H, de Ridder-Sluiter J, van Agt H, Reep-van den Bergh C, van der Stege H, Korfage $\mathrm{I}$, et al. A cluster-randomised trial of screening for language disorders in toddlers. $J$ Med Screen 2004;11:109-16.

16 Buschmann A, Jooss B, Rupp A, Feldhusen F, Pietz J, Philippi H. Parent-based language intervention for two-year-old children with specific expressive language delay: a randomised controlled trial. Arch Dis Child 2008;94:80-2.

17 Girolametto L, Pearce P, Weitzman E. The effects of focused stimulation for promoting vocabulary in children with delays: a pilot study. Journal of Childhood Communication Development 1996;17:39-49.

18 Landry S, Smith K, Swank P, Guttentag C. A responsive parenting intervention: the optimal timing across early childhood for impacting maternal behaviours and child outcomes. Dev Psychol 2008;44:1335-53.

19 Huebner C, Meltzoff A. Intervention to change parent-child reading style: a comparison of instructional methods. Appl Dev Psychol 2005;26:296-313.

20 Law J, Garrett Z, Nye C. The efficacy of treatment for children with developmental speech and language delay/disorder: a meta-analysis [see comment]. J Speech Lang Hear Res 2004;47:924-43.

21 Robertson SB, Weismer SE. Effects of treatment on linguistic and social skills in toddlers with delayed language development. J Speech Lang Hear Res 1999;42:1234-48.

22 Manolson HA, Ward B, Doddington N. You make the difference in helping your child learn. The Hanen Centre, 1995.

23 Dowd T, Withers BE, Hackwood J, Shutter MP. An Australian pilot study of a parent-child interaction program-"You make the difference." Neonat Paediatr Child Health Nurs 2007:10:13-9.

24 Sheehan J, Girolametto L, Reilly S, Ukoumunne OC, Price A, Gold L, et al. Feasibility of a language promotion program for toddlers at risk. Early Childhood Services: An Interdisciplinary Journal of Effectiveness 2009;3:33-50.

25 Australian Bureau of Statistics. Socio-economic indexes for areas. Australian Bureau of Statistics, 2001.

26 Roy P, Kersley H, Law J. The Sure Start language measure standardisation study. 2005. http://tna.europarchive.org/20070101101348/http://www.dfes.gov.uk/research/ programmeofresearch/projectinformation.cfm? projectid $=14628 \&$ resultspage $=1$.

27 Wetherby A, Prizant B. CSBS developmental profile infant/toddler checklist. Paul H Brookes Publishing, 2001.

28 Achenbach TM, Rescorla LA. Manual for ASEBA preschool forms \& profiles. University of Vermont, Research Center for Children, Youth, and Families, 2000.

29 Zimmerman IL, Steiner VG, Pond RE. Preschool language scale. 4th ed. The Psychological Corporation, 2002

30 Reilly S, Eadie P, Bavin EL, Wake M, Prior M, Williams J, et al. Growth of infant communication between 8 and 12 months: a population study. J Paediatr Child Health 2006;42:764-70.

31 Campbell MJ. Cluster randomized trials in general (family) practice research. Stat Methods Med Res 2000;9:81-94

32 Goldstein H. Multilevel statistical models. 3rd ed. Arnold, 2003.

33 Schafer JL. Analysis of incomplete multivariate data. Chapman and Hall, 1997

34 Law J, Garrett Z, Nye C. Speech and language therapy interventions for children with primary speech and language delay or disorder. Cochrane Database Syst Rev 2003;3:CD0004110

35 Miniscalco C, Westerlund M, Lohmander A. Language skills at age 6 years in Swedish children screened for language delay at $21 / 2$ years of age. Acta Paediatrica 2005;94:1798-806

36 Feldman H, Dale PS, Campbell T, Colburn D, Kurs-Lasky M, Rockette H, et al. Concurrent and predictive validity of parent reports of child language at ages 2 and 3 years. Child Dev 2005;76:856-68

37 Fenson L, Bates E, Dale P, Goodman J, Reznick JS, Thal D. Measuring variability in early child language: don't shoot the messenger. Child Dev 2000;71:323-8.

38 Warren S, Fey M, Yoder P. Differential treatment intensity research: a missing link to creating optimally effective communication interventions. Ment Retard Dev Disabil Res Rev 2007;13:70-7.

39 Glogowska M, Roulstone SE, Peters T. Randomised controlled trial of community based speech and language therapy in preschool children. BMJ 2000;321:923-6.

40 Dollaghan $\mathrm{C}$. The handbook for evidence-based practice in communication disorders. Paul H Brookes, 2007.

41 Robey R, Dalebout S. A tutorial on conducting meta-analyses of clinical outcome research. $J$ Speech Lang Hear Res 1998;41:1227-41.

42 Perera R, Heneghan C, Yudkin P. Graphical method for depicting randomised trials of complex interventions. BMJ 2007;334:127-9.

Accepted: 27 June 2011

Cite this as: BMJ 2011;343:d4741 


\section{What is already known on this topic}

Preschool language delay is associated with poorer school and academic performance, more limited employment opportunities, and difficulties with social interactions and relationships

Clinical intervention typically starts late and has limited effect

Selective prevention could start much earlier and reach more children, but its benefits are uncertain

\section{What this study adds}

Population based screening for slow to talk toddlers followed by a group language promotion programme for parents was feasible and acceptable

The programme did not, however, improve language or behaviour either immediately or at age 3 years and would be costly to implement for whole populations

The societal cost of language delay makes further rigorous research into effective prevention and intervention an imperative

\section{Tables}

\begin{tabular}{|c|c|c|}
\hline Characteristics & Intervention arm $(n=158)$ & Control arm $(n=143)$ \\
\hline \multicolumn{3}{|l|}{ Children } \\
\hline Female sex & $76(48)$ & $73(51)$ \\
\hline \multicolumn{3}{|l|}{ Mean (SD) age (months): } \\
\hline At enrolment & $13.3(1.2)$ & $13.3(1.1)$ \\
\hline At baseline & $18.1(0.7)$ & $18.1(0.8)$ \\
\hline At 24 month follow-up questionnaire & $24.6(1.3)$ & $24.5(1.2)$ \\
\hline At 24 month follow-up assessment & $25.4(1.3)$ & $25.1(1.1)$ \\
\hline At 36 month follow-up questionnaire & $36.5(0.8)$ & $36.4(0.7)$ \\
\hline At 36 month follow-up assessment & $37.3(0.6)$ & $37.2(0.7)$ \\
\hline Normally lives with: & $(n=157)$ & $(n=141)$ \\
\hline Both parents & $144(92)$ & $133(94)$ \\
\hline One parent & $10(6)$ & $6(4)$ \\
\hline Other & $3(2)$ & $2(1)$ \\
\hline Hears non-English language $>10$ hours/week & $24(15)$ & 19/142(13) \\
\hline \multicolumn{3}{|l|}{ Mean (SD) baseline measures: } \\
\hline 100 word Sure Start vocabulary & $5.1(2.9)$ & $5.7(3.1)$ \\
\hline $\mathrm{CBCL}$ externalising raw score & $12.9(7.6)$ & $11.9(7.7)$ \\
\hline $\mathrm{CBCL}$ internalising raw score & $6.2(4.5)$ & $5.8(4.3)$ \\
\hline \multicolumn{3}{|l|}{ Parents } \\
\hline Mother's highest level of schooling: & $(n=155)$ & $(n=138)$ \\
\hline Did not complete high school & $16(10)$ & $17(12)$ \\
\hline Completed high school & $68(44)$ & $59(43)$ \\
\hline Tertiary degree/postgraduate & $71(46)$ & $62(45)$ \\
\hline At least one parent in paid work & $142 / 146(97)$ & 135/137 (99) \\
\hline
\end{tabular}

CBCL=Child Behavior Checklist.

Sample size ranged from 133 to 158 in the intervention arm and 124 to 143 in the control arm. 


\begin{tabular}{|c|c|c|c|c|c|}
\hline \multicolumn{6}{|c|}{ Table 2| Outcome comparisons at ages 2 and 3 years } \\
\hline \multirow[b]{2}{*}{ Outcomes } & \multicolumn{2}{|c|}{ Mean (SD) for trial arms } & \multirow[b]{2}{*}{$\begin{array}{l}\text { Unadjusted mean } \\
\text { difference }(I-C)^{*}\end{array}$} & \multicolumn{2}{|l|}{ Adjusted $\dagger$} \\
\hline & Intervention (I) & Control (C) & & $\begin{array}{l}\text { Mean difference (I-C) }(95 \% \\
\mathrm{CI})\end{array}$ & $P$ value \\
\hline \multicolumn{6}{|l|}{2 years } \\
\hline MCDI vocabulary raw score & $34.5(22.4)$ & $34.4(23.4)$ & 0.1 & $2.1(-3.0$ to 7.2$)$ & 0.42 \\
\hline $\begin{array}{l}\text { PLS expressive communication } \\
\text { standard score }\end{array}$ & $90.4(12.9)$ & $90.1(11.2)$ & 0.3 & $1.2(-1.6$ to 4.0$)$ & 0.41 \\
\hline $\begin{array}{l}\text { PLS auditory comprehension standard } \\
\text { score }\end{array}$ & $88.8(15.2)$ & $88.9(14.3)$ & -0.1 & $1.4(-2.2$ to 5.0$)$ & 0.44 \\
\hline $\begin{array}{l}\text { CBCL externalising behaviour raw } \\
\text { score }\end{array}$ & $12.3(7.8)$ & $12.0(7.3)$ & 0.3 & $-0.3(-1.6$ to 1.1$)$ & 0.71 \\
\hline $\begin{array}{l}\mathrm{CBCL} \text { internalising behaviour raw } \\
\text { score }\end{array}$ & $5.7(5.2)$ & $5.4(3.9)$ & 0.3 & $0.1(-0.9$ to 1.1$)$ & 0.78 \\
\hline \multicolumn{6}{|l|}{3 years } \\
\hline MCDI vocabulary raw score & $53.5(27.9)$ & $51.4(25.2)$ & 2.1 & $4.1(-2.3$ to 10.6$)$ & 0.21 \\
\hline $\begin{array}{l}\text { EVT expressive vocabulary standard } \\
\text { score }\end{array}$ & $100.5(15.6)$ & $101.6(12.0)$ & -1.1 & $-0.5(-4.4$ to 3.4$)$ & 0.80 \\
\hline $\begin{array}{l}\text { PLS expressive communication } \\
\text { standard score }\end{array}$ & $97.7(16.1)$ & $100.7(14.0)$ & -3.1 & $-2.4(-6.2$ to 1.4$)$ & 0.21 \\
\hline $\begin{array}{l}\text { PLS auditory comprehension standard } \\
\text { score }\end{array}$ & $96.1(17.5)$ & $97.0(14.7)$ & -0.8 & $-0.3(-4.2$ to 3.7$)$ & 0.90 \\
\hline MCDI sentence use raw score & $5.6(4.1)$ & $5.7(3.8)$ & -0.2 & $0.3(-0.6$ to 1.3$)$ & 0.51 \\
\hline $\begin{array}{l}\text { MCDI language use/complexity raw } \\
\text { score }\end{array}$ & $6.7(2.9)$ & $7.0(2.8)$ & -0.3 & $-0.1(-0.9$ to 0.6$)$ & 0.74 \\
\hline $\begin{array}{l}\text { CBCL externalising behaviour raw } \\
\text { score }\end{array}$ & $10.8(7.9)$ & $10.7(6.9)$ & 0.1 & $-0.1(-1.6$ to 1.4$)$ & 0.86 \\
\hline $\begin{array}{l}\mathrm{CBCL} \text { internalising behaviour raw } \\
\text { score }\end{array}$ & $6.3(5.7)$ & $6.0(4.6)$ & 0.2 & $-0.1(-1.3$ to 1.2$)$ & 0.92 \\
\hline
\end{tabular}

CBCL=Child Behavior Checklist; EVT=Expressive Vocabulary Test; MCDI=MacArthur-Bates Communicative Development Inventory; PLS=Preschool Language Scale.

${ }^{*}$ Sample sizes 135-140 in intervention arm and 133-134 in control arm at 2 years; sample sizes 103-133 in intervention arm and 100-124 in control arm at 3 years. †Sample sizes 119-125 in intervention arm and 121-122 in control arm at 2 years; sample sizes 89-116 in intervention arm and 91-112 in control arm at 3 years. 
Table 3| Intervention parents' subjective evaluation of programme. Values are numbers (percentages)

\begin{tabular}{|c|c|c|c|}
\hline Aspect of programme & No* & Quite/very & Not at all/a little \\
\hline \multicolumn{4}{|l|}{ Evaluation of programme format-How useful was: } \\
\hline Sharing ideas with other parents in programme, before or after sessions & 93 & $71(76)$ & $22(24)$ \\
\hline Sharing ideas with other parents in programme, during group sessions & 99 & $84(85)$ & $15(15)$ \\
\hline Practising programme techniques with my child at end of sessions & 99 & $88(89)$ & $11(11)$ \\
\hline Watching my own DVD clips & 98 & $86(88)$ & $12(12)$ \\
\hline Getting feedback on my interactions with my child during session & 99 & $86(87)$ & $13(13)$ \\
\hline \multicolumn{4}{|l|}{ Evaluation of programme outcomes-The program changed how: } \\
\hline I communicate with my child & 100 & $86(86)$ & $14(14)$ \\
\hline My child communicates with me & 100 & $72(72)$ & $28(28)$ \\
\hline My child behaves with me & 100 & $62(62)$ & $38(38)$ \\
\hline I help my child to behave & 100 & $67(67)$ & $33(33)$ \\
\hline I communicate with my other children & $62 \dagger$ & $47(76)$ & $15(24)$ \\
\hline
\end{tabular}

*100 intervention families provided feedback on programme.

†Question not applicable for 38 families with only one child. 


\section{Figures}

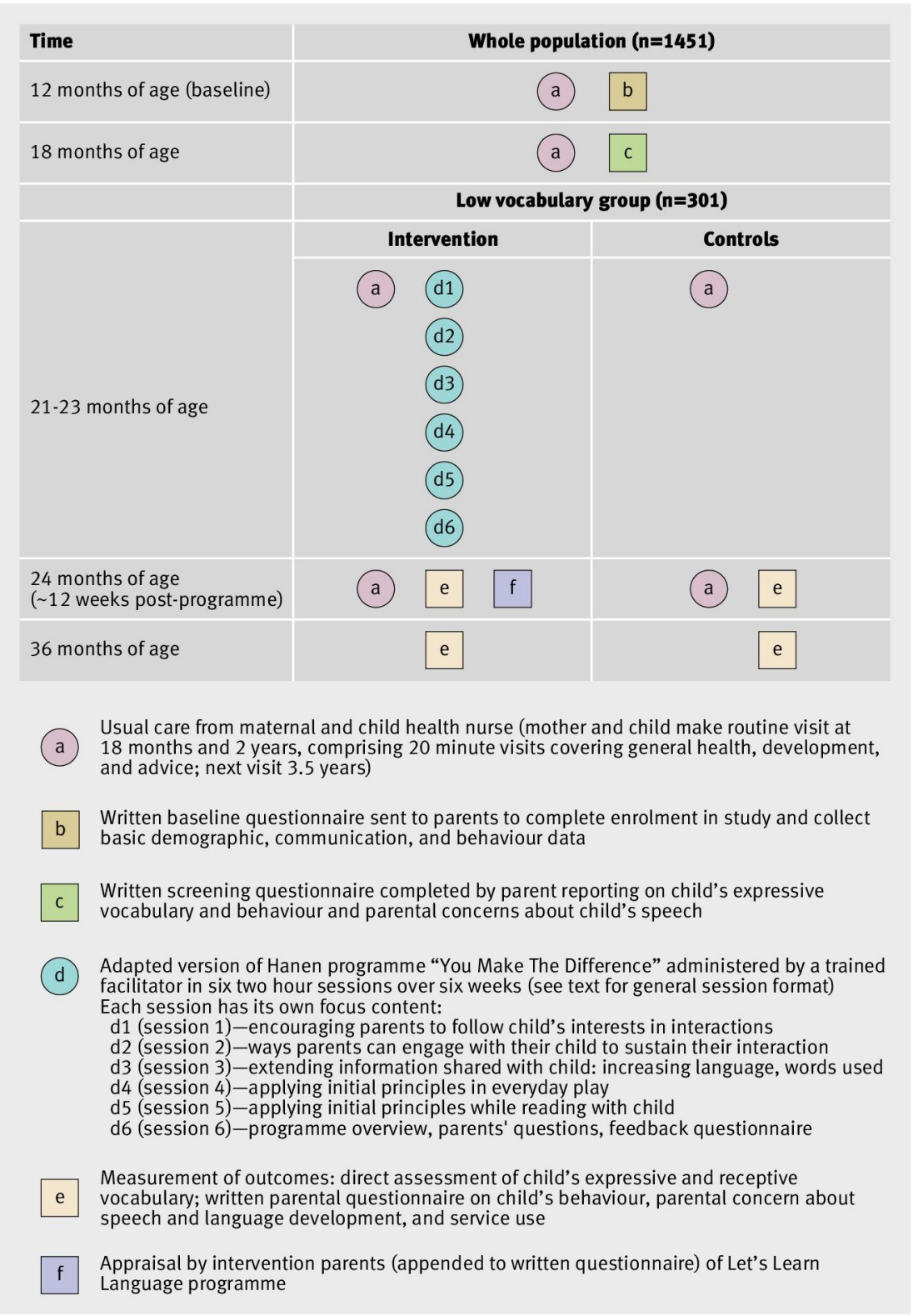

Fig 1 Pictorial diagram ${ }^{42}$ of Let's Learn Language survey and randomised trial 
Eligible for recruitment and baseline survey ( $n=1451)$

\begin{tabular}{|c|c|}
\hline \multicolumn{2}{|c|}{ Eligible for recruitment and baseline survey $(n=1451)$} \\
\hline & $\begin{aligned} \text { Excluded }(n=234): \\
\text { Insufficient English }(n=12) \\
\text { Cleft palate or medical condition }(n=4) \\
\text { Not contactable }(n=21) \\
\text { Did not consent }(n=197)\end{aligned}$ \\
\hline \multicolumn{2}{|c|}{ Enrolled in baseline survey at 12 months ( $n=1217)$} \\
\hline & $\begin{array}{l}\text { Excluded }(n=79) \text { : } \\
\text { Withdrew from study }(n=1) \\
\text { Not contactable }(n=1) \\
\text { Did not return } 18 \text { month survey }(n=77)\end{array}$ \\
\hline \multicolumn{2}{|c|}{ Completed 18 month screening survey $(n=1138)$} \\
\hline & $\begin{array}{c}\text { Ineligble for trial as expressive } \\
\text { vocabulary >20th centile }(n=837)\end{array}$ \\
\hline \multicolumn{2}{|c|}{ Randomised ( $\mathrm{n}=301$ participants and $\mathrm{K}=37$ maternal and child health centre clusters) } \\
\hline$\downarrow$ & \\
\hline \multirow{2}{*}{$\begin{array}{l}\text { Allocated to intervention ( } \mathrm{n}=158 \text { families } \\
\text { and } \mathrm{K}=18 \text { maternal and child health centre } \\
\text { clusters; median cluster size } 8 \text {, range } 5-12) \\
\text { Received at least one session }(n=115) \\
\text { Assigned but did not attend groups ( } \mathrm{n}=38 \text { ) } \\
\text { Declined study, not contactable, or moved } \\
\text { interstate at allocation }(n=5)\end{array}$} & $\begin{array}{l}\text { Allocated to controls ( } n=143 \text { families } \\
\text { and } K=19 \text { maternal and child health centre } \\
\text { clusters; median cluster size } 7 \text {, range } 5-9) \\
\text { Declined study, not contactable, or moved } \\
\text { interstate at allocation }(n=3)\end{array}$ \\
\hline & \\
\hline \multicolumn{2}{|l|}{ r } \\
\hline $\begin{array}{l}24 \text { month outcome data provided }(n=148) \\
24 \text { month outcome data not provided }(n=5) \text { : } \\
\text { Uncontactable or moved away }(n=2) \\
\text { Withdrew from study ( } n=1) \\
\text { Declined visit and no survey }(n=2)\end{array}$ & $\begin{array}{l}24 \text { month outcome data provided }(\mathrm{n}=137) \\
24 \text { month outcome data not provided }(\mathrm{n}=3) \text { : } \\
\text { Uncontactable }(\mathrm{n}=1) \\
\text { Withdrew from study }(\mathrm{n}=2)\end{array}$ \\
\hline \multicolumn{2}{|l|}{$\downarrow$} \\
\hline $\begin{array}{l}\text { Analysed ( } \mathrm{n}=148 \text { families and } \mathrm{K}=17 \text { maternal } \\
\text { and child health centre clusters; median cluster } \\
\text { size } 9, \text { IQR } 5-12 \text {, range } 2-21 \text { ) }\end{array}$ & $\begin{array}{l}\text { Analysed ( } \mathrm{n}=137 \text { families and } \mathrm{K}=19 \text { maternal } \\
\text { and child health centre clusters; median cluster } \\
\text { size } 7, \text { IQR 5-8, range } 1-17 \text { ) }\end{array}$ \\
\hline$\downarrow$ & $\downarrow$ \\
\hline $\begin{array}{l}36 \text { month outcome data provided }(n=140) \\
36 \text { month outcome data not provided }(n=8) \text { : } \\
\text { Withdrew from study }(n=4) \\
\text { Declined visit and no survey }(n=4)\end{array}$ & \multirow[t]{2}{*}{$\begin{array}{l}36 \text { month outcome data provided }(n=127) \\
36 \text { month outcome data not provided }(n=10) \text { : } \\
\text { Uncontactable or moved away }(n=2) \\
\text { Withdrew from study }(n=6) \\
\text { Declined visit and no survey }(n=2)\end{array}$} \\
\hline & \\
\hline † & $\downarrow$ \\
\hline $\begin{array}{c}\text { Analysed ( } \mathrm{n}=140 \text { families and } \mathrm{K}=17 \text { maternal } \\
\text { and child health centre clusters; median cluster } \\
\text { size } 9, \text { IQR } 5-11 \text {, range } 2-20 \text { ) }\end{array}$ & $\begin{array}{c}\text { Analysed ( } \mathrm{n}=127 \text { families and } \mathrm{K}=19 \text { maternal } \\
\text { and child health centre clusters; median cluster } \\
\text { size } 6, I Q R 4-8 \text {, range } 1-16)\end{array}$ \\
\hline
\end{tabular}

Fig 2 Participant flow chart for Let's Learn Language survey and randomised trial. IQR=interquartile range 